\title{
Remanufacturing of end-of-life glass-fiber reinforced composites via UV-assisted 3D printing
}

\author{
Andrea Mantelli, Marinella Levi, Stefano Turri and Raffaella Suriano \\ Department of Chemistry, Materials and Chemical Engineering "Giulio Natta", Politecnico di Milano, Milano, Italy
}

\begin{abstract}
Purpose - The purpose of this study is to demonstrate the potential of three-dimensional printing technology for the remanufacturing of end-of-life (EoL) composites. This technology will enable the rapid fabrication of environmentally sustainable structures with complex shapes and good mechanical properties. These three-dimensional printed objects will have several application fields, such as street furniture and urban renewal, thus promoting a circular economy model.

Design/methodology/approach - For this purpose, a low-cost liquid deposition modeling technology was used to extrude photo-curable and thermally curable composite inks, composed of an acrylate-based resin loaded with different amounts of mechanically recycled glass fiber reinforced composites (GFRCs). Rheological properties of the extruded inks and their printability window and the conversion of cured composites after an ultraviolet light (UV) assisted extrusion were investigated. In addition, tensile properties of composites remanufactured by this UV-assisted technology were studied.

Findings - A printability window was found for the three-dimensional printable GFRCs inks. The formulation of the composite printable inks was optimized to obtain high quality printed objects with a high content of recycled GFRCs. Tensile tests also showed promising mechanical properties for printed GFRCs obtained with this approach.

Originality/value - The novelty of this paper consists in the remanufacturing of GFRCs by the three-dimensional printing technology to promote the implementation of a circular economy. This study shows the feasibility of this approach, using mechanically recycled EoL GFRCs, composed of a thermoset polymer matrix, which cannot be melted as in case of thermoplastic-based composites. Objects with complex shapes were threedimensional printed and presented here as a proof-of-concept.
\end{abstract}

Keywords Composites, Mechanical properties, Rheology, Recycling, Circular economy

Paper type Research paper

\section{Introduction}

Over the past century, the impact of human activity on the environment has been enormously increasing (Wackernagel and Rees, 1996). The extensive exploitation of fossil derivatives for the production of polymer materials is an example of the humanity role played in this respect (Sikdar, 2003). Moreover, the controversial environmental sustainability of synthetic polymers is not only limited to their production but also to the disposal of end-of-life (EoL) products (Barnes et al., 2009).

The recyclability of fiber-reinforced polymers, which are a peculiar class of engineering materials, is dramatically poor when compared to commodity thermoplastics because of their inherent multi-material nature (Yang et al., 2012). In the EU, more than one million of tons of composite waste were produced in 2015[1]. Moreover, an increasing amount of these products is reaching their EoL, which usually occurs after periods of 10 years for recreational boats and 30 years for sails and wind turbine blades[1]. In light of this, the question of how to recover, recycle and reuse composites needs to be addressed (Pickering, 2006; Yang et al., 2012).

The current issue and full text archive of this journal is available on Emerald Insight at: https://www.emerald.com/insight/1355-2546.htm

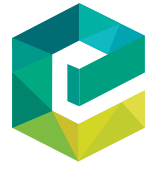

Rapid Prototyping Journal

26/6 (2020) 981-992

Emerald Publishing Limited [ISSN 1355-2546]

[DOI 10.1108/RPJ-01-2019-0011]
Composite materials are often landfilled at the end of their life, following the "take, make and dispose" model of the current linear economy, which unsustainably consumes natural resources, manufactures and discards products (Ayre, 2018)[2]. However, aiming at a circular economy model, technologies used for the manufacturing of products should recover materials through the reuse, recycling, repairing and remanufacturing, thus reducing waste and possibly without downcycling materials (Oliveux et al., 2015). Many studies have been conducted to

\footnotetext{
(C) Andrea Mantelli, Marinella Levi, Stefano Turri and Raffaella Suriano. Published by Emerald Publishing Limited. This article is published under the Creative Commons Attribution (CC BY 4.0) licence. Anyone may reproduce, distribute, translate and create derivative works of this article (for both commercial and non-commercial purposes), subject to full attribution to the original publication and authors. The full terms of this licence may be seen at http://creativecommons.org/licences/by/4.0/legalcode

The authors acknowledge financial support from Horizon 2020 European project "FiberEUse, Large scale demonstration of new circular economy value-chains based on the reuse of end-of-life fiber reinforced composites" (call H2020-CIRC-2016TwoStage, Project Number 730323). They also would like to thank Giacomo Bonaiti and Rivierasca S.p.A. for the recycled materials kindly supplied. Moreover, the authors would like to thank Elena Paracchini for her Master Thesis work, entitled "MIDA Additive re-manufacturing and circular economy of composite materials, Re-Manifattura Additiva ed Economia Circolare di Materiali Compositi”.
}

Received 11 January 2019

Revised 12 June 2019

Accepted 7 July 2019 
develop new methods to recycle composites with the aim of recovering high-value materials and reducing damage to the fibers (Henshaw et al., 1996). However, some of these strategies have scale-up problems due to high maintenance costs for the equipment and high-energy demands. Consequently, high recycling costs can outweigh any economic benefits. These issues should be overcome to include composites into the circular economy model (Mativenga et al., 2017).

This is particularly true for glass fiber reinforced composites (GFRCs) because the required investment can exceed the intrinsic value of recovered products, thus, creating a barrier to the real industrial adoption of any recycling technologies. While the recycling of carbon fibers is a well-established practice (Longana et al., 2016; Wang et al., 2018), it is still an economic challenge for glass fibers, although the production volume of GFRCs in Europe is at least one order of magnitude higher than carbon fiber reinforced polymers (CFRPs) [1]. GFRCs with a polymeric matrix can be recycled through several methods, e.g. mechanical grinding, pyrolysis (Åkesson et al., 2012; Pickering et al., 2000) and solvolysis (Iwaya et al., 2008). In some cases, the recovered materials can be reused for new products by splitting, hot and cold crushing and hot forming (Adams et al., 2015). One of the few methods that reached industrial applications is the mechanical recycling leading to different qualities and dimensions of recyclates to be reused (Shuaib and Mativenga, 2016). Recycled glass fibers can be used as fillers in thermoplastics or as short fibers in thermoset composites manufactured with several production techniques, such as sheet molding compound and bulk molding compound (Beauson et al., 2014). Kouparitsas et al. (2002) analyzed several materials recovered from grinding (mechanical recycling). They demonstrated that ground recycled composites found a good reuse in thermoplastic-based composites prepared by compression molding.

Recently, additive manufacturing is an emergent technology for the production of composite components through the successive addition of material (Anwer and Naguib, 2018; Blok et al., 2018; Brenken et al., 2018; Sano et al., 2018; Yang et al., 2017), leaving wide freedom in terms of shape and complexity (Compton and Lewis, 2014; Griffini et al., 2016). This manufacturing technology enables to reduce the costs in the design-to-prototype phase of product development, while reducing the scraps (Wang et al., 2017). Another big advantage is the customization of products based on the final user needs, for instance, customized prostheses, splints and arm casts (Chen et al., 2016; Ostuzzi et al., 2015; Paterson et al., 2015; Zhang and Kwok, 2017). Recent studies have demonstrated the possibility of using waste polymers or recyclates to produce filaments for low-cost, rapid prototypers and three-dimensional printers (Baechler et al., 2013; Cruz Sanchez et al., 2017; Czyżewski et al., 2018; Zander et al., 2018). Very recently, continuous carbon fiber reinforced thermoplastic composites have been recycled and remanufactured by means of fused deposition modeling (FDM) technology (Tian et al., 2017). Indeed, Tian et al. started from three-dimensional printed carbon fiber reinforced polylactide composites to obtain an impregnated carbon fiber filament, which was reused into the additive remanufacturing process. However, no researchers have yet performed studies on the recycling and reprocessing of mechanically recycled glass fiber reinforced thermoset composites by three-dimensional printing.

In the present work, an additive remanufacturing process for GFRCs was proposed and investigated to reuse shredded solid recyclates recovered from GFRCs. To the best of our knowledge, this paper is the first study in the literature on the remanufacturing of glass fiber reinforced acrylate-based composites by an innovative three-dimensional printing process. Starting from ground glass fiber thermoset composites and a photo-curable resin, a remanufacturing procedure was developed for GFRCs by exploiting the versatility of UVassisted three-dimensional printing via liquid deposition modeling (LDM) technology. A solvent- and styrene-free resin loaded with recycled GFRCs was selected for its environmental sustainability. This material was optimized in terms of different component percentages, rheological properties and printability of extruded liquid inks, as well as UV conversion of printed cured materials. Then, the mechanical properties of recycled GFRCs reprocessed by UV-assisted three-dimensional printing were studied. Based on these results, a new promising approach for the low-cost recycling and fabrication of composite components was presented and examined to pave the way for future developments of three-dimensional printed highperformance composites.

\section{Materials and methods}

Milled virgin glass fibers, hereinafter called FIL 100, were supplied by Italdry, Italy (Italdry FIL 100, with a diameter of $13 \mu \mathrm{m}$ and a nominal length of $100 \mu \mathrm{m}$ ). Recycled GFRCs powders, consisted of a styrene-based unsaturated polyester resin originally reinforced with $5 \mathrm{~cm}$ long fibers with a diameter of $13 \mu \mathrm{m}$, were supplied by Rivierasca S.p.A., Italy. The glass content of the recycled powder was evaluated by thermogravimetric analysis (TGA) and the corresponding curves are shown in the supplementary material (Figure S1). Table I shows the main characteristics of the fillers used. The ethoxylate bisphenol A diacrylate resin, hereinafter named SR349, was purchased from Arkema, (local distributor: Came S.r.l., Italy). Butanediol dimethacrylate (BDDMA) and dicumyl peroxide were purchased from Sigma-Aldrich, Italy. Ethyl phenyl (2, 4, 6trimethyl benzoyl) phosphinate, named TPO-L, was purchased from Lambson Limited, UK. All products were used as received.

Table I Glass fiber content (estimated by thermogravimetric analysis), mean Feret's diameter (estimated by optical microscope images) for mechanically recycled GFRCs, fiber length $(I)$, fiber diameter $(d)$ and geometry factor $(\zeta)$, both for virgin glass fibers (estimated by optical microscope images and as reported in datasheet) and for recycled GFRC powder (estimated by scanning electron microscopy analysis)

\begin{tabular}{lccccc}
\hline & Glass fiber content [\%] & $\begin{array}{c}\text { Mean Feret's diameter } \\
{[\mu \mathrm{m}]}\end{array}$ & $\begin{array}{c}\text { Fiber length, } \\
I[\mu \mathrm{m}]\end{array}$ & $\begin{array}{c}\text { Fiber width, } \\
\mathbf{w}[\mu \mathbf{m}]\end{array}$ & $\begin{array}{c}\text { Geometry factor, } \zeta \\
\left(\mathbf{2}^{*} I / w\right)\end{array}$ \\
\hline $\begin{array}{l}\text { Virgin glass fiber (FIL 100) } \\
\text { Recycled GFRC powder }\end{array}$ & 100 & N.A. & $42.2 \pm 30.5$ & 13 (nominal diameter) & $6.5 \pm 4.7$ \\
\hline
\end{tabular}


Different percentages of a reactive diluent (BDDMA) with respect to SR349 (0, 10 and $20 \%$ wt.) were investigated. SR349 and BDDMA were mixed in the selected proportions with a magnetic stirrer at room temperature for $30 \mathrm{~min}$. Later, $3 \% \mathrm{wt}$. of the photoinitiator (TPO-L) and $0.3 \% \mathrm{wt}$. of the thermal initiator (dicumyl peroxide) with respect to the total weight of the resin system (reactive components + initiators) were added. Then, the mixture was mechanically stirred at room temperature for $2 \mathrm{~h}$. Figure 1a shows the chemical scheme for the crosslinking reaction of the resin. The photoinitiator, the thermal initiator and their concentrations were selected on the basis of UV light system used for UV-assisted three-dimensional printing, to obtain the best printability results and minimize the presence of unreacted groups in the resin (for further details please see supplementary material and Figure S2). FIL 100 glass fibers were added to the resin and manually mixed until a material with good processability was obtained. The mechanically recycled GFRC was mixed either with a mechanical stirrer equipped with a shear stress impeller for $4 \mathrm{~h}$ at $250 \mathrm{rpm}$ or with a Brabender mixer (C. W. Brabender Instruments, Inc., USA) equipped with rollerblade for $45 \mathrm{~min}$ at $40 \mathrm{rpm}$. Figure $1 \mathrm{~b}$ shows the formulations studied in this work and obtained either with the mechanical stirrer or with the Brabender mixer (for brevity, from here on the formulations of three-dimensional printable inks will be referred to as XDYR, where $\mathrm{X}$ indicates the percentage of reactive diluent and $Y$ the concentration of recycled GFRCs).

3Drag three-dimensional printer was supplied by Futura Group Srl, Italy. The setup of the printer was the same used by Griffini et al. (2016), except for the UV light system composed of three light emitting diodes (LEDs) with a light emission peaked at $395 \mathrm{~nm}$, controlled with the dimmable driver LED DI001LE supplied by Tecno Switch, Italy.

Reactivity measurements were carried out by Ultraviolet light-differential scanning calorimetry (UV-DSC) analyzes with a Mettler-Toledo DSC/823e, Mettler Toledo, USA, equipped with Lightningcure LC8, Hamamatsu Photonics, Japan. UV-DSC tests were performed exposing the samples for
$3 \mathrm{~min}$ to a $365 \mathrm{~nm} \mathrm{UV}$ radiation $\left(607.7 \mathrm{~mW} / \mathrm{cm}^{2}\right)$ twice. The difference in enthalpy between the first and the second runs was used to measure the UV conversion. DSC tests were performed under $\mathrm{N}_{2}$ environment with the following heating/cooling ramps: from $25^{\circ} \mathrm{C}$ to $250^{\circ} \mathrm{C}$ with a $10 \%$ min heating rate, from $250^{\circ} \mathrm{C}$ to $0^{\circ} \mathrm{C}$ with a $20^{\circ} / \mathrm{min}$ cooling rate and from $0^{\circ}$ to $250^{\circ} \mathrm{C}$ with a $20 \% \mathrm{~min}$ heating rate. The exothermic heat flow because of the polymerization of unreacted groups was measured in the first ramp. The glass transition temperature of the material was evaluated in the second heating ramp.

Fourier transform infrared (FTIR) spectroscopy was used to determine the presence of unreacted groups in threedimensional printed specimens before and after UV postcuring, as well as after thermal post-curing by means of Thermo Nicolet Nexus 670 FTIR spectrometer with an attenuated total reflectance (ATR) module equipped with a Germanium crystal. FTIR spectra were acquired with a resolution of $4 \mathrm{~cm}^{-1}$ and 64 scans. Spectra automatic smoothing and baseline correction were performed with Omnic $^{\mathrm{TM}}$ software.

Thermogravimetric analyzes were performed with TA INSTRUMENTS Q500 TGA, TA Instruments, Inc., USA. The samples were heated from $25^{\circ} \mathrm{C}$ to $800^{\circ} \mathrm{C}$ with a $25^{\circ} \mathrm{C} / \mathrm{min}$ heating rate under an air environment.

The UV post-curing treatment was performed with a UV chamber Polymer $500 \mathrm{~W}$, Helios Italquartz S.r.1., Italy, equipped with a UVA emittance mercury vapor lamp type $\mathrm{Zs}\left(950 \mathrm{~W} / \mathrm{m}^{2}\right)$, for $5 \mathrm{~min}$ each side. For the thermal postcuring treatment, samples were heated in an oven for $2 \mathrm{~h}$ at $140^{\circ} \mathrm{C}$.

Rheological tests were carried out with Kinexus DSR, Malvern Panalytical Ltd., UK. Before the measurements, a conditioning step was applied: a constant shear stress was firstly applied for $1 \mathrm{~min}$ (10 Pa for samples with 30 and $40 \%$ wt. of recycled GFRCs, 1,000 $\mathrm{Pa}$ for samples with 45, 50 and $55 \%$ wt. of recycled GFRCs), followed by $3 \mathrm{~min}$ rest period. All measurements were performed with a $20 \mathrm{~mm}$ plate-plate

Figure 1 Compositions of the recycled GFRCs

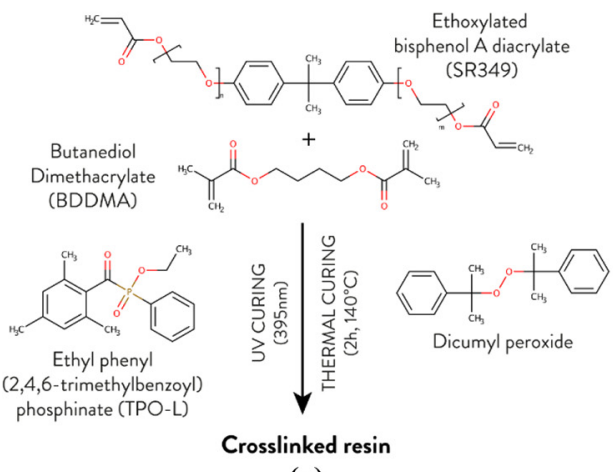

(a)

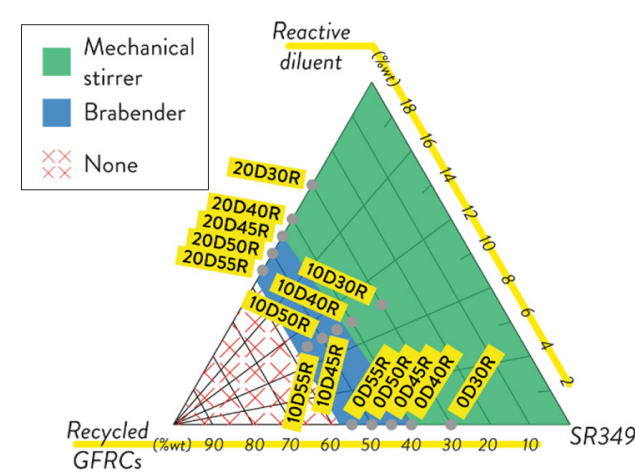

(b)

Notes: (a) Chemical structures of reagents used to obtain a neat resin sample and a thermoset composite matrix; (b) composition graph where the printable ink formulations analyzed in this work are highlighted in yellow. The green and blue areas respectively indicate the compositions of materials mixed with a mechanical stirrer and a Brabender mixer, while the white area with red crosses shows where no good processability, after mixing, was attainable for inks 
geometry and a $0.7 \mathrm{~mm}$ gap. After the rest period, a stress ramp test was performed from 10 to $20,000 \mathrm{~Pa}$ in $20 \mathrm{~min}$ (when $1,000 \mathrm{~Pa}$ pre-shear was applied the stress ramp measurement was started from $100 \mathrm{~Pa}$ ).

Tensile mechanical properties were measured by means of Zwick Roell Z010, ZwickRoell GmbH \& Co. KG, Germany, equipped with a $10 \mathrm{kN}$ cell load. The tests were performed following the ASTM standard test method D638 - 14 (2014)[3] and D3039/D3039M-17 (2017) [4]. The former was used for the neat resin, $0 \mathrm{D} 10 \mathrm{R}$ and $0 \mathrm{D} 50 \mathrm{~V}(\mathrm{~V}$ stands for virgin glass fibers) both cast and three-dimensional printed specimens. In this case, specimens had a gauge length of $50 \mathrm{~mm}$, a width of $13 \mathrm{~mm}$, an overall length of $165 \mathrm{~mm}$ and a thickness of $3 \mathrm{~mm}$. The test speed was $5 \mathrm{~mm} / \mathrm{min}$. The latter standard was used for threedimensional printed 20D45R specimens, with a gauge length of $30 \mathrm{~mm}$, a width of $15 \mathrm{~mm}$, an overall length of $100 \mathrm{~mm}$ and a thickness of $3 \mathrm{~mm}$. The test speed was $2 \mathrm{~mm} / \mathrm{min}$ in this case. All the three-dimensional printed specimens were manually polished to eliminate typical roughness because of three-dimensional printing manufacturing.

The elastic modulus was predicted by using the Halpin-Tsai model and the equations used are shown in the supplementary material.

Olympus BX60, Olympus Corp., Japan, was used to acquire optical micrographs with 50 and 100x magnification.

SEM images were obtained with Cambridge Stereoscan 360, Cambridge Instrument Company Ltd., UK. All the SEM images were obtained using a secondary electron probe. Sample surfaces for the SEM analysis were prepared with a physical vapor deposition of gold for $1 \mathrm{~min}$.

\section{Results and discussion}

\subsection{Printability and rheological characterization}

UV-assisted three-dimensional printing process enables the extrusion of photo-curable inks with different compositions and viscosities by varying the process parameters. However, several tests were performed in this study to evaluate the optimal parameters for three-dimensional printing of materials with different concentrations of recycled GFRCs and rheological behaviors. As shown in Figure 2, the best printability results were achieved with the composition 20D45R because the entire printed object was flawless in this case (for brevity, the formulations of three-dimensional printable inks are referred to as $\mathrm{XDYR}$, where $\mathrm{X}$ indicates the percentage of the reactive diluent and $Y$ the concentration of recycled GFRCs).

Moreover, to obtain high quality printed objects with complex shapes, the three-dimensional printing apparatus presented by Griffini et al. (2016) was modified, as shown in Figures $3 \mathrm{a}$ and $3 \mathrm{~b}$. The apparatus previously presented by Griffini and coworkers was composed of two UV LEDs. However, this caused some problems during a few preliminary trials to print recycled GFRCs. Indeed, UV light did not properly irradiate the photo-curable extruded ink because the already printed materials overshadowed some regions of the extruded liquid ink, thus causing poor crosslinking and a collapse of the extruded material (Figure 3c). Because of the addition of a third UV-LED and a specific support for the three LEDs (Figure 3b), it was possible to enhance the homogeneous distribution of the UV radiation and to consequently three-dimensional print flawless complex shapes (Figure 3d).

In an LDM-based printing process, the study of the rheological behavior of printable inks is crucial because ink viscosity influences its flow through the extrusion nozzle, hence, affecting the printability of extruded inks and the possibility to obtain threedimensional objects. To analyze the rheological behavior of different printable inks, several compositions were investigated at varying the percentage of the reactive diluent and recycled GFRCs. Figure 4 shows the results of rheological stress ramp tests. All the compositions exhibited a Newtonian behavior at low shear rates and a pseudoplastic shear-thinning behavior at higher shear rates. Although the values of viscosity in the Newtonian plateau raised by increasing the content of recycled GFRCs, they reduced by increasing the content of the reactive diluent, keeping the percentage of GFRCs constant. The rheological stress ramp curves were merged with results obtained with the printability tests, to determine a printability window for the recycled GFRC inks, highlighted in gray in Figure 4. All the inks with 40, 45 and $50 \%$ wt. of recycled GFRCs and OD30R samples were found three-dimensional printable. On the other hand, formulations with 10 or $20 \%$ wt. of reactive diluent and $30 \%$ wt. of recycled

Figure 2 Printability tests with different material formulations and their corresponding printing parameters, i.e. extrusion flow and nozzle diameter

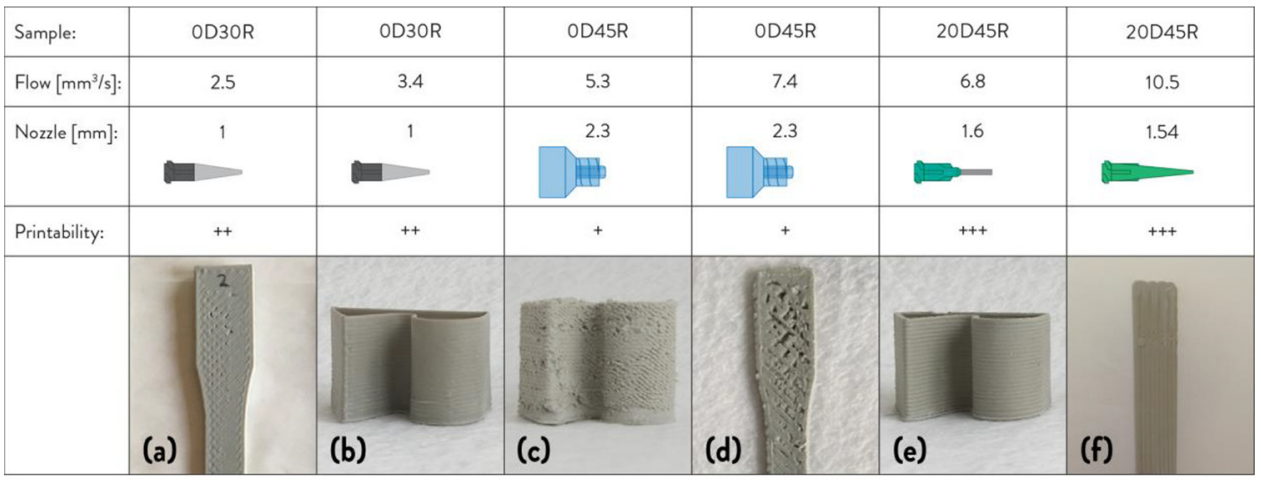

Notes: (a) OD30R dumbbell specimen; (b) OD30R demonstrator; (c) 0D45R demonstrator;

(d) 0D45R dumbbell specimen; (e) 20D45R demonstrator; (f) 20D45R tensile test bar specimen 
Figure 3 UV-assisted three-dimensional printing apparatus

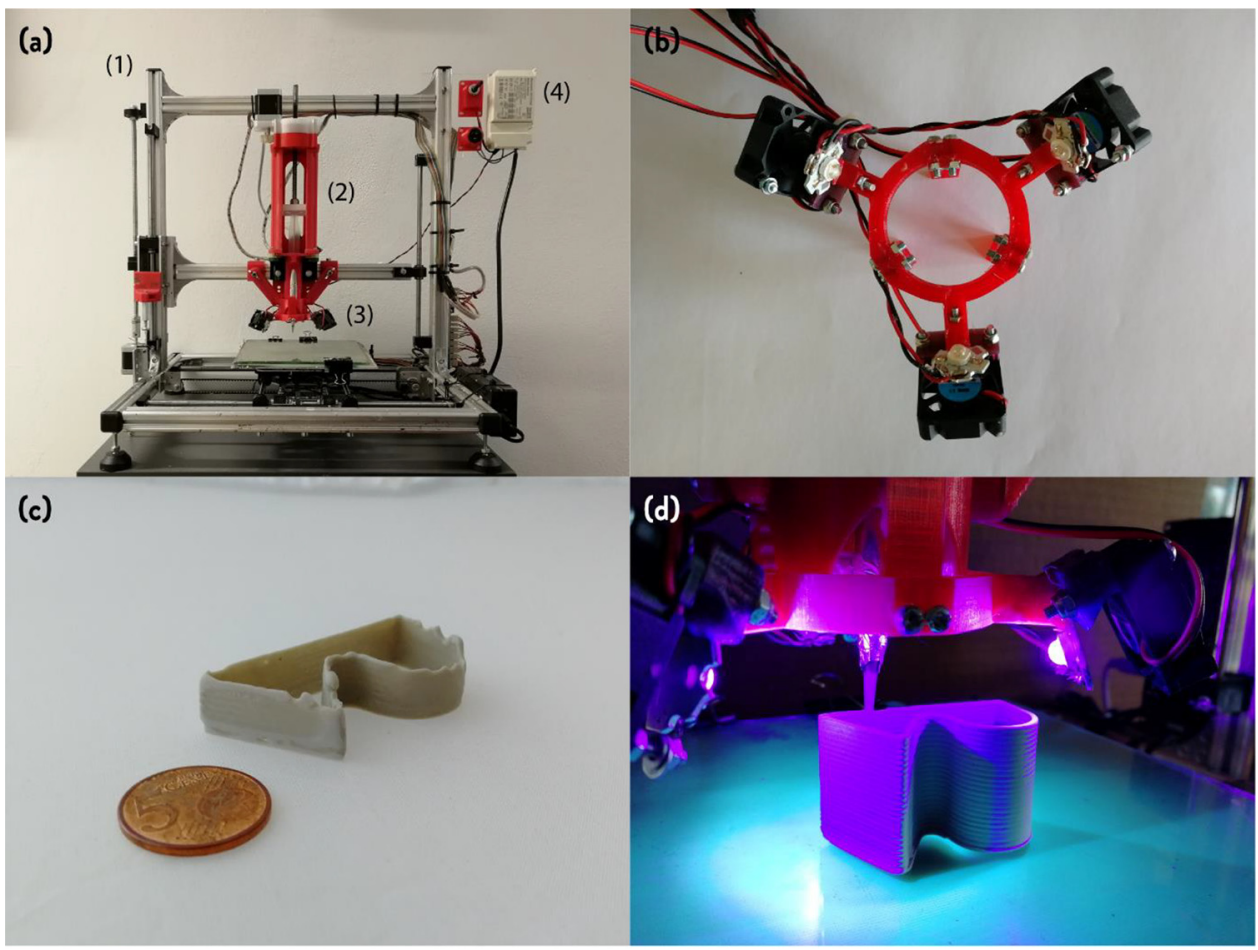

Notes: (a) Apparatus with a (1) 3Drag printer structure, (2) extrusion system, (3) UV-LED system, (4) LED driver; (b) detail of the modified UV-LED system; (c) a preliminary sample printed with a 3D printing apparatus previously presented (Griffini et al., 2016); (d) a 3D printed object obtained after modifying the UV-LED system

Figure 4 Stress ramp test results for three-dimensional printable inks

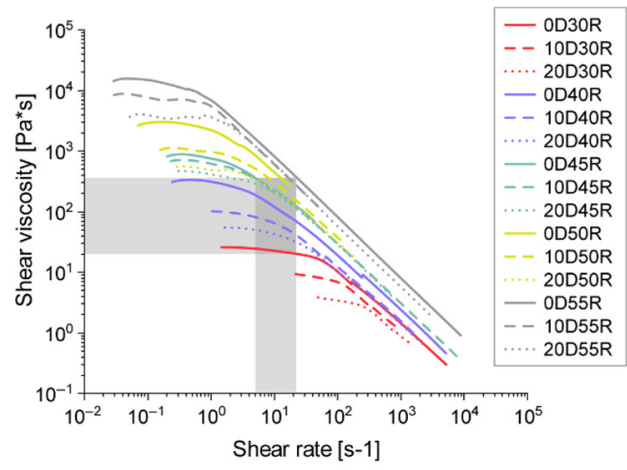

(a)

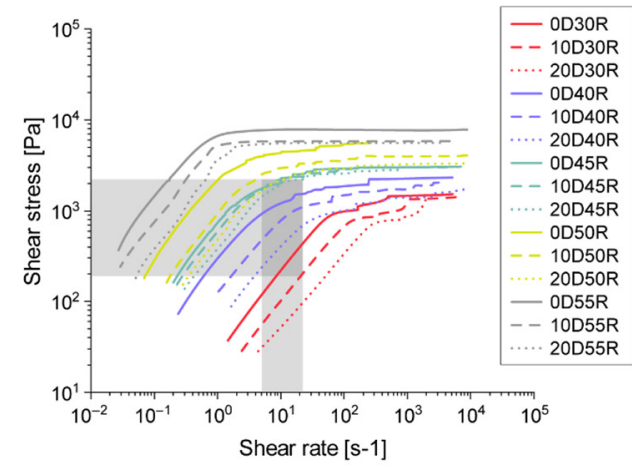

(b)

Notes: (a) Shear viscosity vs shear rate; (b) shear stress vs shear rate. The printability windows are highlighted in gray

GFRCs exhibited a low value of viscosity, which led to an uncontrolled extrusion and a poor shape retention. Moreover, the level of viscosity for inks with $55 \%$ wt. of recycled GFRCs was very high, and therefore, not compatible with our extrusion printing system, which was not able to process them.
Nevertheless, surface quality and final appearance of threedimensional printed objects are important parameters to be considered. As already shown in Figure 2, although 0D45R inks were three-dimensional printable and their printability was highlighted in Figure 4, surface quality of the 
corresponding printed objects was poor (Figure 5b). Indeed, the mixed material was discontinuous and fractured after extrusion, even though it had a good processability before extrusion. Figure $5 \mathrm{c}$ shows that the addition of $20 \%$ wt. of the reactive diluent BDDMA allowed the ink with $45 \%$ wt. of recycled GFRCs (20D45R) to be more easily extruded and printed with an astonishingly good surface quality, at a higher extrusion rate, and consequently, higher shear rate than $0 \mathrm{D} 45 \mathrm{R}$.

\subsection{Chemical and physical characterization}

During UV-assisted three-dimensional printing processes, curable materials rapidly become solid after extrusion by means of UV irradiation, which triggers a crosslinking reaction. However, the retention of the shape of an extruded material can be affected by the conversion of the UV-induced crosslinking reaction. Accordingly, the UV conversion for the three-dimensional printable inks and printed materials under investigation in this study was analyzed by means of UV-DSC analyzes.

The UV conversion was calculated with the following equation (1):

$$
U V_{\text {conv. }}=\frac{\Delta H_{\text {sample }}}{\Delta H_{\text {neat resin }}} \times 100
$$

where $\Delta H_{\text {sample }}$ is the enthalpy of the sample and $\Delta H_{\text {neat resin }}$ is the enthalpy of the resin system without recycled GFRCs.
As shown in Figure $6 \mathrm{a}$, the UV conversion of threedimensional printable inks was slightly lowered by increasing the recycled GFRC content.

Considering the three-dimensional printed samples, the residual conversion (residual enthalpy of three-dimensional printed samples) is approximately 10 per cent, apart from samples with $55 \%$ wt. of recycled GFRCs that showed an average residual UV conversion of 35 per cent. Consequently, a good shape retention of the extruded material can be achieved for three-dimensional printable inks with a recycled GFRC content ranging from 10 to $45 \%$ wt. because they exhibited a low residual UV conversion. On the other hand, higher values of residual conversion for samples with the $55 \% \mathrm{wt}$. of recycled GFRCs confirmed their printability issues, also determined by rheological analyzes.

However, as shown in Figure 6a, a small portion of the unreacted acrylic groups in the three-dimensional printed composite acrylate-based matrix was still present. Consequently, all the three-dimensional printed samples were exposed to a UV post-curing treatment after three-dimensional printing, to enhance the UV conversion. After UV post-curing, DSC analysis were performed to check the presence of any residual reactive groups. As shown in Figure 6b, two exothermic peaks were observed by DSC measurements because of the polymerization of unreacted groups. At lower contents of recycled GFRCs, an evident peak appeared at approximately $185^{\circ} \mathrm{C}$. By increasing the content of recycled GFRCs, another peak appeared at lower temperatures,

Figure 5 Compositions, three-dimensional printed objects and their corresponding process parameters for three three-dimensional printable inks

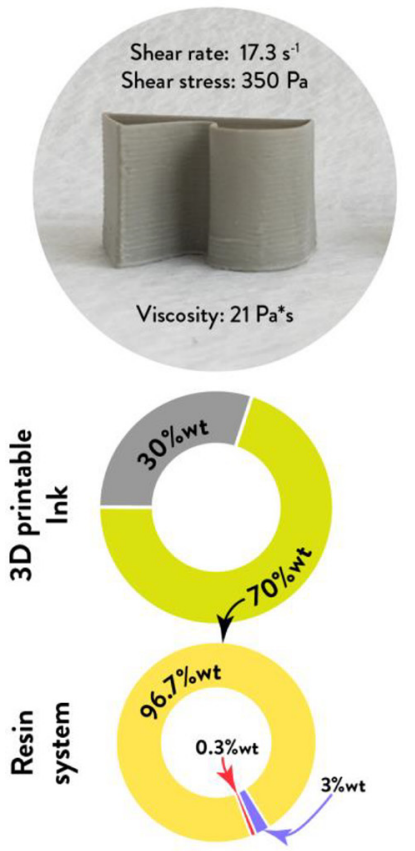

(a)

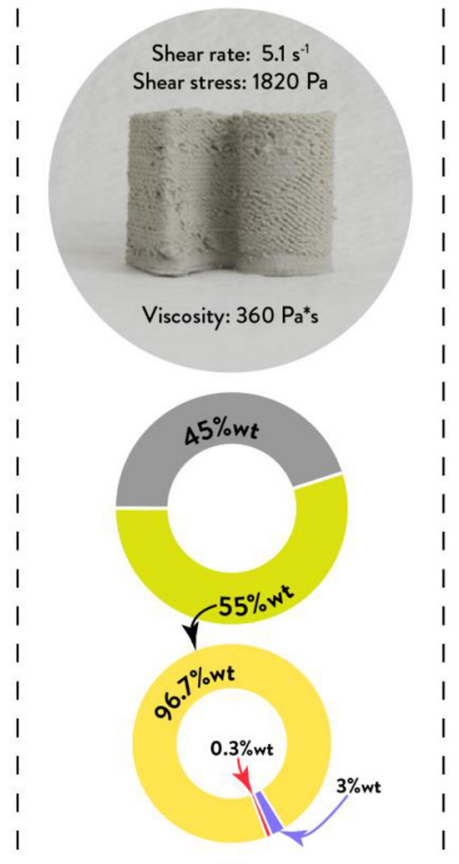

(b)

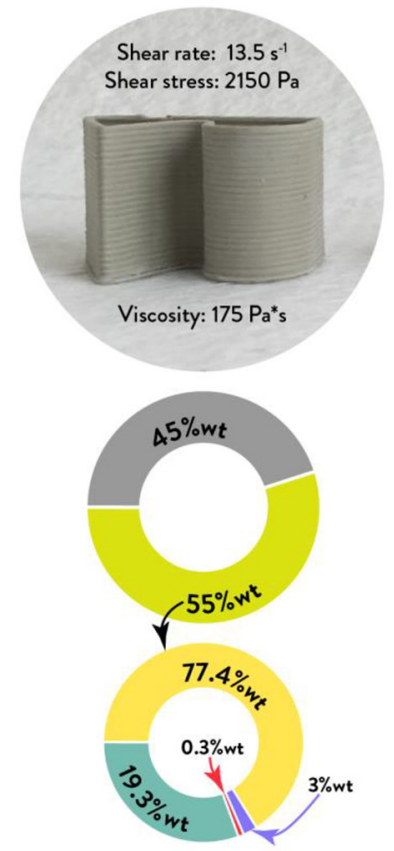

(c)

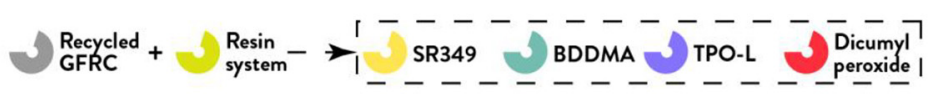

Notes: (a) 0D30R; (b) 0D45R; (c) 20D45R 
Figure 6 DSC analyzes for three-dimensional printable and printed materials with different percentages of recycled GFRCS

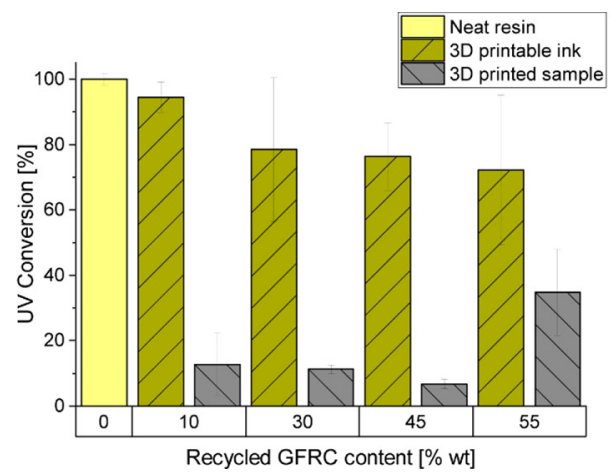

(a)

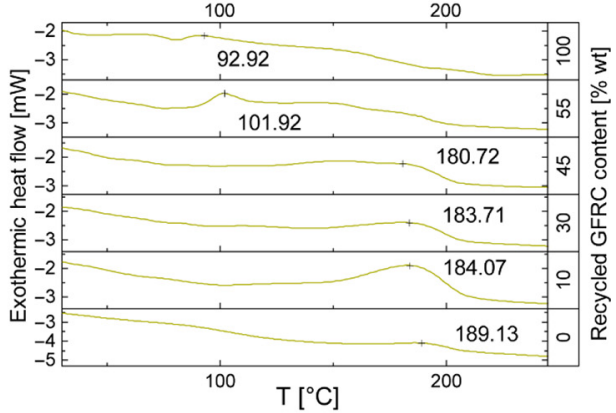

(b)

Notes: (a) UV conversion of 3D printable inks and of 3D printed samples evaluated by UV-DSC;

(b) DSC first heating ramps, which show the presence of exothermic peaks for 3D printed samples after a UV post-curing treatment

approximately at $100^{\circ} \mathrm{C}$. Comparing the three-dimensional printed composites with the neat resin and recycled GFRCs, the presence of a lower temperature peak can be attributed to the presence of unreacted groups inside the recycled GFRC polyester-based matrix, while the higher temperature peak was because of unreacted acrylate groups. As a result of this, a thermal post-curing treatment at $140^{\circ} \mathrm{C}$ for $2 \mathrm{~h}$ was performed to minimize the presence of unreacted groups in the final threedimensional printed composites. The absence of any exothermic enthalpies in DSC analysis performed for samples after thermal post-curing confirmed the beneficial effect of this thermal treatment. The presence of unreacted acrylate groups after three-dimensional printing, after UV post-curing and after thermal post-curing was also monitored for 20D30R sample by FTIR spectroscopy, as shown in the supplementary material (Figure S3). FTIR spectra confirmed the presence of some unreacted acrylate groups in the sample after threedimensional printing and their reduction after UV and thermal post-curing.

The glass transition temperature, $T_{g}$ of the three-dimensional printed composites was measured after UV and thermal postcuring by means of DSC analysis. The measurements were performed for the samples with a content of recycled GFRCs ranging from 10 to $55 \% \mathrm{wt}$. The values of $T_{g}$ resulting from these tests were found comparable for all samples and an average value of $105 \pm 4^{\circ} \mathrm{C}$ was calculated.

\subsection{Mechanical characterization}

Mechanical properties were investigated only for threedimensional printed composites, which showed a good surface quality after three-dimensional printing, as previously discussed and shown in Figure 5. Two formulations of three-dimensional printed composites were, therefore, selected, namely, 0D30R; and 20D45R (Figures 5a and 5c, respectively, for further details about the compositions). Two formulations with $50 \%$ wt. of milled virgin glass fibers were also used as a benchmark. From now on three-dimensional printed and cast samples with $50 \%$ wt. of virgin glass fibers will be referred to as $0 \mathrm{D} 50 \mathrm{~V}$ (3D) and 0D50V (C), respectively.
Although the content of glass fibers inside the threedimensional printed composites with recycled GFRCs is low (less than $10 \%$ wt. Figure S1), mechanical properties were overall good when compared to neat resin and virgin fiber composites. Indeed, the values of tensile strength for 20D45R printed samples were comparable with those measured for 0D50V (three-dimensional) and slightly lower than the cast neat resin. Moreover, the same trend was found for the values of strain at failure. Samples composed of neat resin exhibited an elongation at break slightly higher than the printed composite samples, possibly because of the premature failure due to the presence of defects in remanufactured composite samples.

As for the elastic properties, Young's modulus increased by raising the glass fiber content, as shown in Figure $7 \mathrm{~b}$. All experimental values of elastic modulus measured for the composite samples were also confirmed by the theoretical values predicted by using the Halpin-Tsai model (Figure 7b). By using recycled GFRCs with a higher content of glass fibers, a higher elastic modulus comparable to that for virgin glass fiber reinforced samples used as a benchmark can be easily achieved in next works.

\subsection{Morphological characterization}

Filler particle dimensions were measured by optical microscopy. The recycled GFRC powders showed a mean particle Feret's diameter equal to $3.5 \pm 4.2 \mu \mathrm{m}$. The distribution of particle Feret's diameters of the recycled GFRCs was reported in the supplementary materials (Figure S4). The length of FIL 100 glass fibers was measured for the material as supplied and after the three-dimensional extrusion process to check if there was any effect on the fiber length. The results show that the average length of virgin glass fibers decreased from $70.8 \pm 63.1 \mu \mathrm{m}$ to $42.2 \pm 30.6 \mu \mathrm{m}$ after three-dimensional printing. The maximum fiber length was 622 and $410 \mu \mathrm{m}$ before and after threedimensional printing, respectively. The three-dimensional printing process had, therefore, an effect on the length of virgin glass fibers. The micrographs and the distribution of the fiber length values before and after three-dimensional printing were shown in the supplementary material (Figure S4). 
Figure 7 Tensile test results

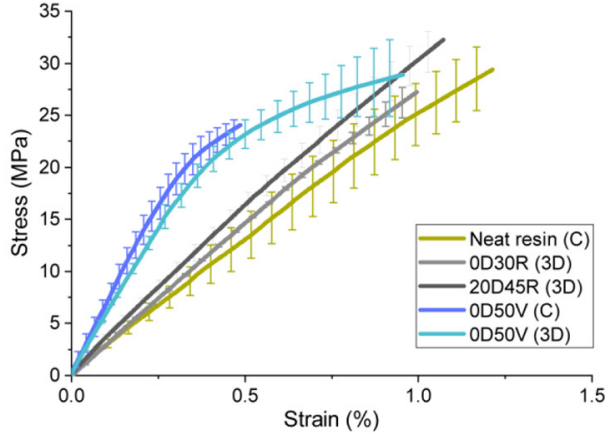

(a)

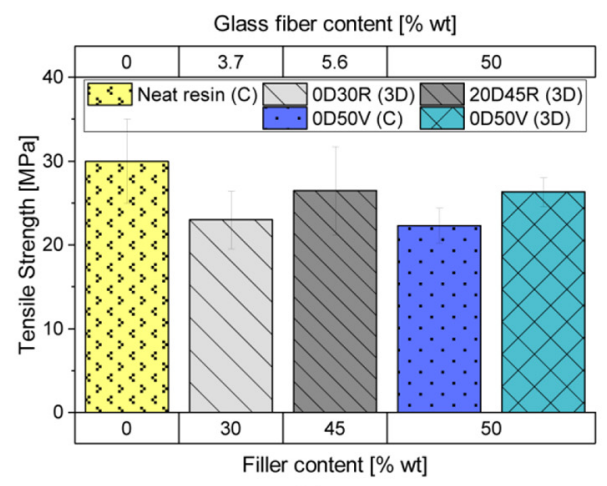

(c)

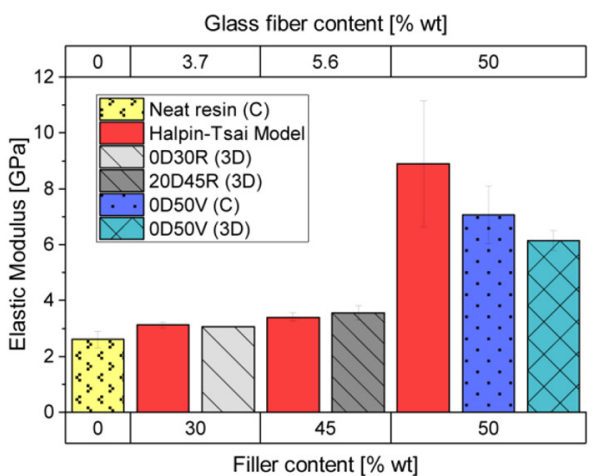

(b)

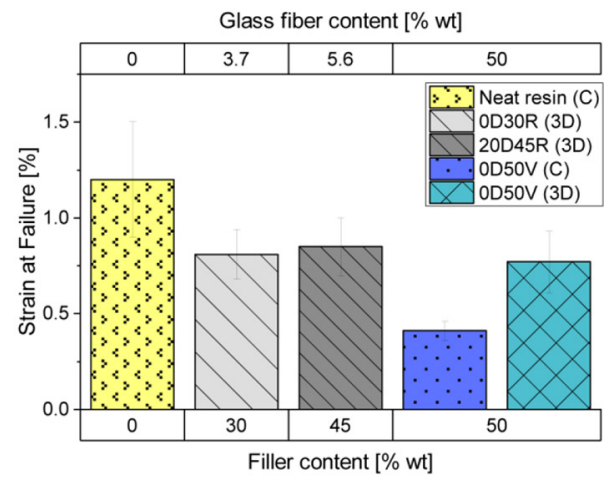

(d)

Notes: (a) Average experimental tensile test curves; (b) experimental values of elastic modulus with theoretical values predicted by employing halpin-tsai model; (c) experimental values of ultimate tensile strength; (d) experimental values of strain at failure

Glass fiber dimensions in recycled GFRCs were determined by scanning electron microscopy. Figures $8 \mathrm{a}$ and $8 \mathrm{~b}$ highlight the presence of broken glass fibers inside the mechanically recycled GFRCs.

A fractured cross-section of a tensile test specimen 20D45R (three-dimensional) showed an intact fiber, whose diameter was $13.5 \mu \mathrm{m}$, suggesting that some fibers were not impaired after the recycling process (Figure $8 \mathrm{c}$ ).

\subsection{Additive remanufacturing}

To improve the surface finish of printed structures, a polishing treatment and a successive gel coat application either on the polished surface or on a polished and painted surface were performed, as shown in Figure 9. Because of these surface treatments, the three-dimensional printed objects not only attained a reduction of surface roughness but also an enhanced environmental resistance and a decorative perspective. Moreover, the printability of objects three-dimensional printed in both spiral and conventional modes was investigated and achieved. Infill patterns were successfully printed inside the structures with the conventional three-dimensional printing mode. Usually, such infill patterns are effectively printed in an FDM process, using the recoil movement of the filament. However, the possibility to suddenly stop the material outflow and move the nozzle to another position was not available in the LDM process developed in this work. However, this did not prevent the three-dimensional printing of high-quality objects with infill patterns through the LDM process in the conventional mode, as shown in Figures 9d, 9e and 9f.

To exploit these printable recycled GFRC materials, adopting a circular economy approach, different application fields were considered. Figure 10a shows different concepts of application for three-dimensional printed recycled GFRCs, presenting several sketches of outdoor architecture and scenography elements of an amusement park. Indeed, outdoor architecture for public and private infrastructures such as benches and rest areas can be built by threedimensional printing of recycled composites. Another example of application for the three-dimensional printable composite materials is the fabrication of scenography elements of an amusement park because these structures can be very complex and usually unique. Accordingly, they can be suitably produced using a large volume three-dimensional printer, by means of a robotic arm equipped with an extrusion head. The three-dimensional printing process presented in this work can be easily scaled up to meet the requirements for the additive manufacturing of large objects because of its simplicity. 
Figure 8 SEM micrographs with details of glass fibers

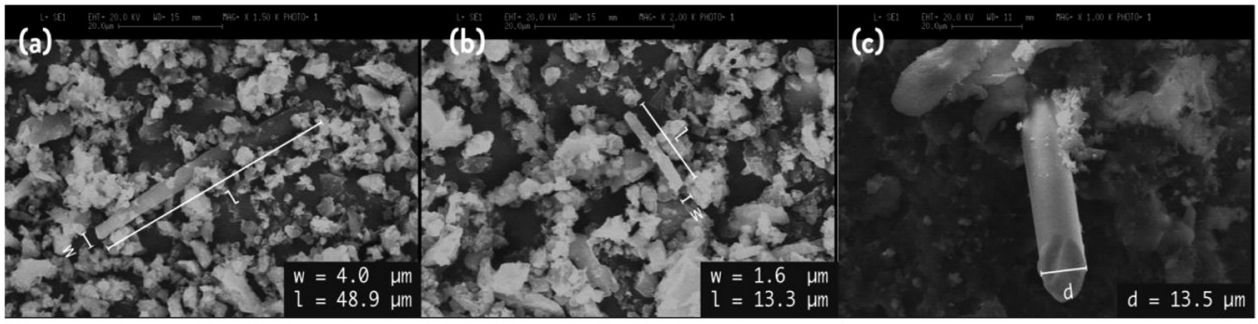

Notes: (a) and (b) recycled GFRC powder; (c) 20D45R (three-dimensional) specimen fractured section

Figure 9 Surface finish for objects printed in spiral mode and in conventional mode with infill patterns

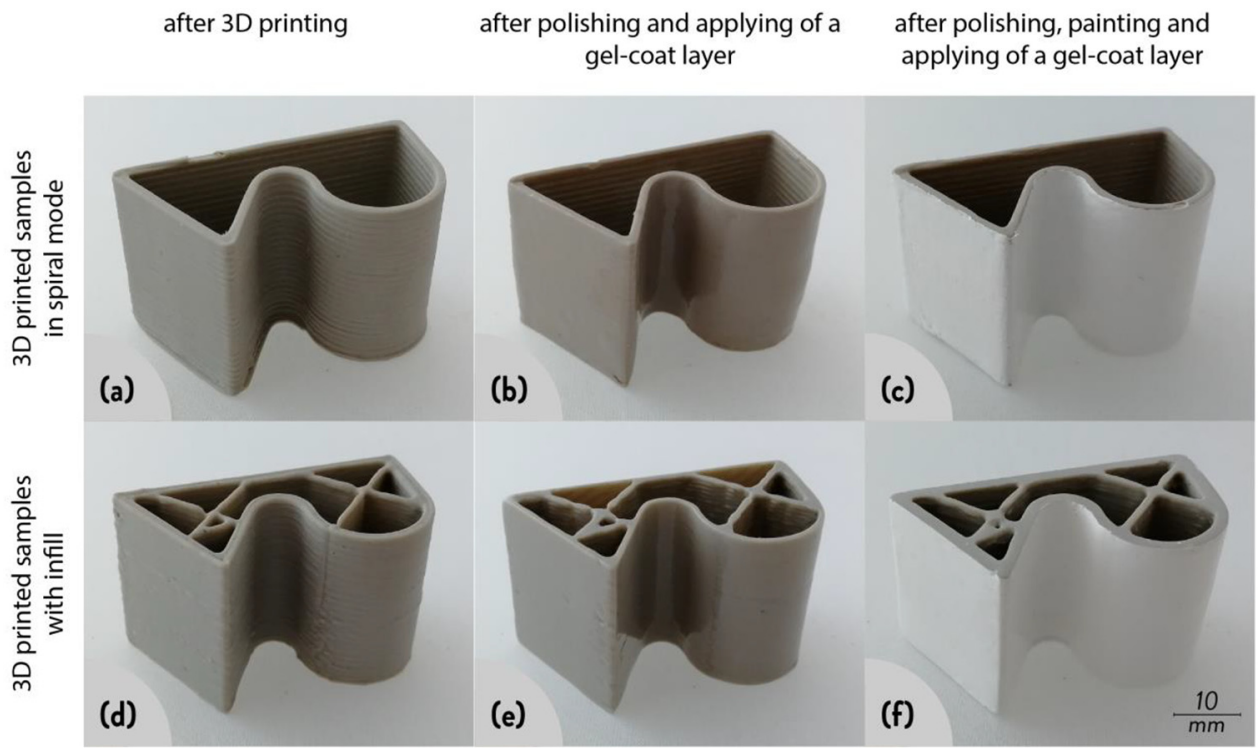

Notes: (a) Objects printed in spiral mode after 3D printing; (b) after polishing and a gel coat application; (c) after polishing, painting and a gel coat application; (d) objects printed in conventional mode with infill patterns after 3D printing; (e) after polishing and a gel coat application; (f) after polishing, painting and a gel coat application

As shown in Figures $10 \mathrm{~b}$ and $10 \mathrm{c}$, overhangs with a tilt angle of $30^{\circ}$ with respect to the printing surface were printed by UV-assisted LDM process, without any need of supporting structures, commonly used in FDM process. This result was achieved only because of a fine-tuning of process parameters such as a rapid and effective UV crosslinking of the resin during the LDM extrusion process. As a proof-of-concept, a scale model of a main entrance for an amusement park was three-dimensional printed with the ink 20D45R (Figure 10d). The UV-assisted printing process of the scale model presented in Figure 10c and d was also shown in Movie S1 (Supplementary Material).

\section{Conclusions}

In this paper, an additive remanufacturing process was developed and validated for the production of polymer composite structures, using mechanically recycled GFRCs as fillers and an environmentally sustainable resin as matrix, thus implementing a circular economy model. To obtain a three-dimensional printable GFRC with a high glass transition temperature, an acrylate-based resin rapidly photo-curable through a LDM printing process was selected and optimized. The addition of a reactive diluent in the resin system and the concentration of recycled GFRCs in the composite printable inks were found to significantly affect the quality of three-dimensional printed objects. A UV-assisted three-dimensional printing of composites with a high content of recycled GFRCs was successfully achieved by adding a $20 \% \mathrm{wt}$. of reactive diluent. Rheological characterization of the printable inks at varying recycled GFRC and reactive diluent concentrations was performed to find a printability window 
Figure 10 Additive remanufacturing
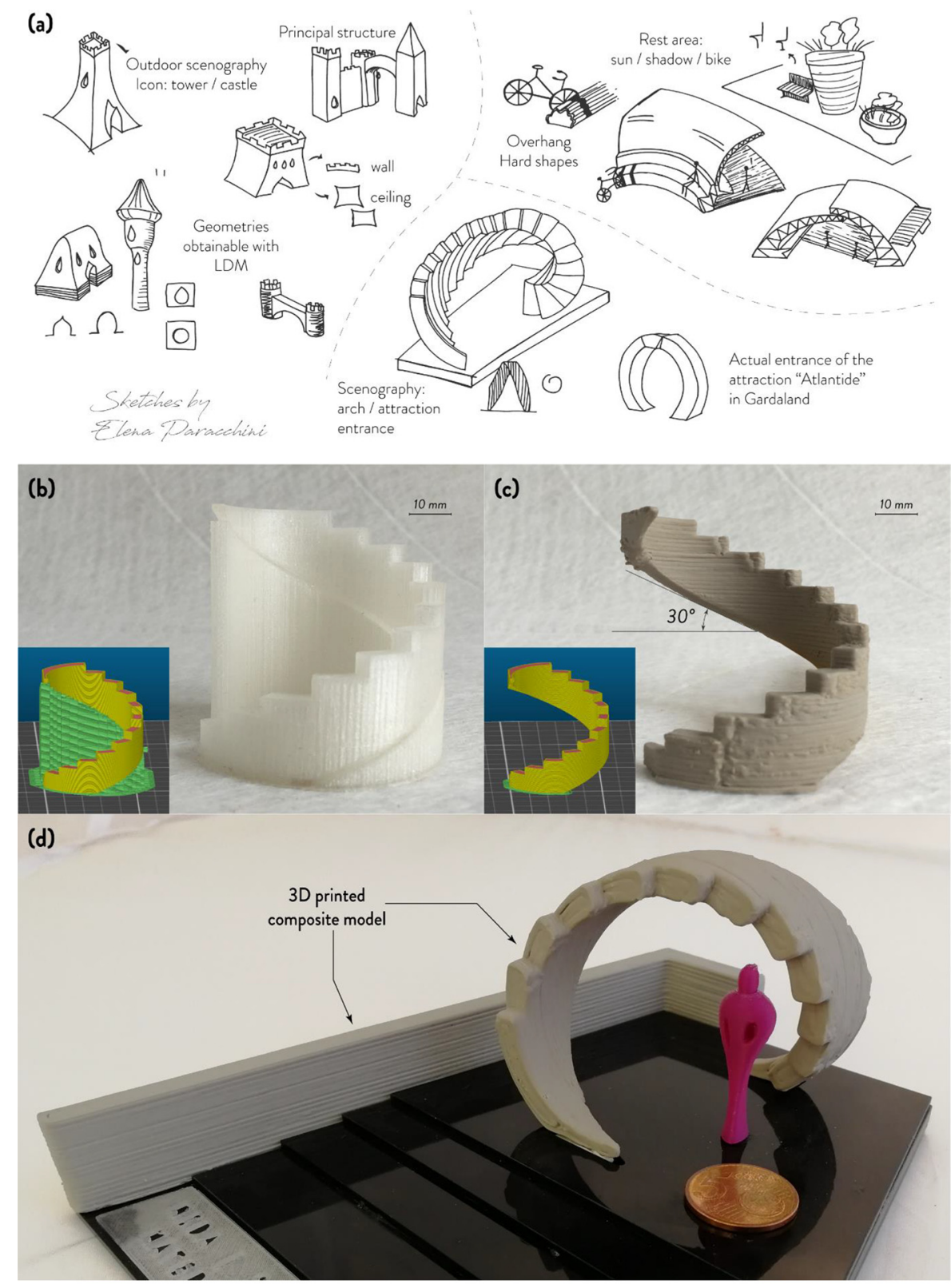

Notes: (a) Design concepts of amusement park attractions and outdoor architecture; three-dimensional printed structures with the corresponding G-Code in the inset obtained; (b) by the FDM process; (c) by the LDM process; (d) a printed scale model of a main entrance of an amusement park

for these systems. The printability window of the composite inks was determined on the basis of the shear rate estimated in the extrusion nozzle. A UV and thermal post-curing enabled the increase of crosslinking degree and the minimization of residual unreacted groups in the three-dimensional printed composites. Three-dimensional printed GFRCs also showed promising mechanical properties, which can be enhanced by selecting composite waste with higher glass fiber contents. The results of this work show for the first time that a low-cost UV-assisted three-dimensional printing technology can be used for the remanufacturing of GFRCs and some complex structures were printed as a proof-of-concept. This study opens the way towards the re-introduction of GFRC waste from diverse application fields (e.g. wind turbines blade and construction components) to the production cycle of high-performance composites. 


\section{Notes}

1 AVK and Carbon Composites, Composites Market Report 2017. www.eucia.eu/userfiles/files/20170919_avkccev_market _report_2017.pdf. (accessed 8 December 2018).

2 World Economic Forum, Ellen MacArthur Foundation and McKinsey \& Company, The new plastics economy rethinking the future of plastics, available at: www. ellenmacarthurfoundation.org/publications/the-new-plasticseconomy-rethinking-the-future-of-plastics (accessed 4 December 2018).

3 ASTM D638, Standard Test Method for Tensile Properties of Plastics, (2014), available at: (www.astm.org/ Standards/D638.htm).

4 ASTM D3039, Standard Test Method for Tensile Properties of Polymer Matrix Composite Materials, (2017), available at: www.astm.org/Standards/D3039.htm

\section{References}

Adams, R.D., Collins, A., Cooper, D., Digby, M.W., Farmer, A.W., Laurence, A., Patel, K., Stevens, M. and Watkins, R. (2015), "28 - Recycling of reinforced plastics", in Beaumont, P.W.R., Soutis, C. and Hodzic, A. (Eds), Structural Integrity and Durability of Advanced Composites, Woodhead Publishing, Cambridge, pp. 763-792.

Åkesson, D., Foltynowicz, Z., Christéen, J. and Skrifvars, M. (2012), "Microwave pyrolysis as a method of recycling glass fibre from used blades of wind turbines", fournal of Reinforced Plastics and Composites, Vol. 31 No. 17, pp. 1136-1142.

Anwer, A. and Naguib, H.E. (2018), "Multi-functional flexible carbon fiber composites with controlled fiber alignment using additive manufacturing", Additive Manufacturing, Vol. 22, pp. 360-367.

Ayre, D. (2018), "Technology advancing polymers and polymer composites towards sustainability: a review", Current Opinion in Green and Sustainable Chemistry, Vol. 13, pp. 108-112.

Baechler, C., DeVuono, M. and Pearce, J.M. (2013), "Distributed recycling of waste polymer into RepRap feedstock", Rapid Prototyping fournal, Vol. 19 No. 2, pp. 118-125.

Barnes, D.K.A., Galgani, F., Thompson, R.C. and Barlaz, M. (2009), "Accumulation and fragmentation of plastic debris in global environments", Philosophical Transactions of the Royal Society B: Biological Sciences, Vol. 364 No. 1526, pp. 1985-1998.

Beauson, J., Lilholt, H. and Brøndsted, P. (2014), "Recycling solid residues recovered from glass fibre-reinforced composites - a review applied to wind turbine blade materials", fournal of Reinforced Plastics and Composites, Vol. 33 No. 16, pp. 1542-1556.

Blok, L.G., Longana, M.L., Yu, H. and Woods, B.K.S. (2018), "An investigation into 3D printing of fibre reinforced thermoplastic composites”, Additive Manufacturing, Vol. 22, pp. 176-186.

Brenken, B., Barocio, E., Favaloro, A., Kunc, V. and Pipes, R.B. (2018), "Fused filament fabrication of fiber- reinforced polymers: a review", Additive Manufacturing, Vol. 21, pp. 1-16.

Chen, R.K., Jin, Y-A., Wensman, J. and Shih, A. (2016), "Additive manufacturing of custom orthoses and prostheses a review", Additive Manufacturing, Vol. 12, pp. 77-89.

Compton, B.G. and Lewis, J.A. (2014), "3D-Printing of lightweight cellular composites”, Advanced Materials, Vol. 26 No. 34, pp. 5930-5935.

Cruz Sanchez, F.A., Boudaoud, H., Hoppe, S. and Camargo, M. (2017), "Polymer recycling in an open-source additive manufacturing context: mechanical issues", Additive Manufacturing, Vol. 17, pp. 87-105.

Czyżewski, P., Bieliński, M., Sykutera, D., Jurek, M., Gronowski, M., Ryl, Ł. and Hoppe, H. (2018), "Secondary use of ABS co-polymer recyclates for the manufacture of structural elements using the FFF technology", Rapid Prototyping Fournal, Vol. 24 No. 9, pp. 1447-1454.

Griffini, G., Invernizzi, M., Levi, M., Natale, G., Postiglione, G. and Turri, S. (2016), "3D-printable CFR polymer composites with dual-cure sequential IPNs", Polymer, Vol. 91, pp. 174-179.

Henshaw, J.M., Han, W. and Owens, A.D. (1996), “An overview of recycling issues for composite materials", fournal of Thermoplastic Composite Materials, Vol. 9 No. 1, pp. 4-20.

Iwaya, T., Tokuno, S., Sasaki, M., Goto, M. and Shibata, K. (2008), "Recycling of fiber reinforced plastics using depolymerization by solvothermal reaction with catalyst", Fournal of Materials Science, Vol. 43 No. 7, pp. 2452-2456.

Kouparitsas, C.E., Kartalis, C.N., Varelidis, P.C., Tsenoglou, C.J. and Papaspyrides, C.D. (2002), "Recycling of the fibrous fraction of reinforced thermoset composites", Polymer Composites, Vol. 23 No. 4, pp. 682-689.

Longana, M.L., Ong, N., Yu, H. and Potter, K.D. (2016), "Multiple closed loop recycling of carbon fibre composites with the HiPerDiF (high performance discontinuous fibre) method", Composite Structures, Vol. 153, pp. 271-277.

Mativenga, P.T., Sultan, A.A.M., Agwa-Ejon, J. and Mbohwa, C. (2017), "Composites in a circular economy: a study of United Kingdom and South Africa", Procedia Cirp, Vol. 61, pp. 691-696.

Oliveux, G., Dandy, L.O. and Leeke, G.A. (2015), “Current status of recycling of fibre reinforced polymers: review of technologies, reuse and resulting properties", Progress in Materials Science, Vol. 72, pp. 61-99.

Ostuzzi, F., Rognoli, V., Saldien, J. and Levi, M. (2015), "+TUO project: low cost 3D printers as helpful tool for small communities with rheumatic diseases", Rapid Prototyping fournal, Vol. 21 No. 5, pp. 491-505.

Paterson, A.M., Bibb, R., Campbell, R.I. and Bingham, G. (2015), "Comparing additive manufacturing technologies for customised wrist splints", Rapid Prototyping fournal, Vol. 21 No. 3, pp. 230-243.

Pickering, S.J. (2006), "Recycling technologies for thermoset composite materials - current status", Composites Part A: Applied Science and Manufacturing, Vol. 37 No. 8, pp. 1206-1215.

Pickering, S.J., Kelly, R.M., Kennerley, J.R., Rudd, C.D. and Fenwick, N.J. (2000), "A fluidised-bed process for the recovery of glass fibres from scrap thermoset composites", Composites Science and Technology, Vol. 60 No. 4, pp. 509-523. 
Sano, Y., Matsuzaki, R., Ueda, M., Todoroki, A. and Hirano, Y. (2018), "3D printing of discontinuous and continuous fibre composites using stereolithography", Additive Manufacturing, Vol. 24, pp. 521-527.

Shuaib, N.A. and Mativenga, P.T. (2016), "Effect of process parameters on mechanical recycling of glass fibre thermoset composites", Procedia Cirp, Vol. 48, pp. 134-139.

Sikdar, S.K. (2003), "Sustainable development and sustainability metrics", AIChE fournal, Vol. 49 No. 8, pp. 1928-1932.

Tian, X., Liu, T., Wang, Q., Dilmurat, A., Li, D. and Ziegmann, G. (2017), "Recycling and remanufacturing of 3D printed continuous carbon fiber reinforced PLA composites", Fournal of Cleaner Production, Vol. 142, pp. 1609-1618.

Wackernagel, M. and Rees, W. (1996), Our Ecological Footprint: Reducing Human Impact on the Earth, Gabriola Island, B.C., New Society Publishers.

Wang, X., Jiang, M., Zhou, Z., Gou, J. and Hui, D. (2017), "3D printing of polymer matrix composites: a review and prospective”, Composites Part B: Engineering, Vol. 110, pp. 442-458.

Wang, S., Xing, X., Zhang, X., Wang, X. and Jing, X. (2018), "Room-temperature fully recyclable carbon fibre reinforced phenolic composites through dynamic covalent boronic ester bonds", fournal of Materials Chemistry A, Vol. 6 No. 23, pp. 10868-10878.

Yang, Y., Boom, R., Irion, B., van Heerden, D.-J., Kuiper, P. and de Wit, H. (2012), "Recycling of composite materials", Chemical Engineering and Processing: Process Intensification, Vol. 51, pp. 53-68.

Yang, C., Tian, X., Liu, T., Cao, Y. and Li, D. (2017), “3D printing for continuous fiber reinforced thermoplastic composites: mechanism and performance", Rapid Prototyping fournal, Vol. 23 No. 1, pp. 209-215.

Zander, N.E., Gillan, M. and Lambeth, R.H. (2018), "Recycled polyethylene terephthalate as a new FFF feedstock material", Additive Manufacturing, Vol. 21, pp. 174-182.

Zhang, Y. and Kwok, T.H. (2017), "An interactive product customization framework for freeform shapes", Rapid Prototyping Fournal, Vol. 23 No. 6, pp. 1136-1145.

\section{Corresponding author}

Raffaella Suriano can be contacted at: raffaella.suriano@, polimi.it 